\title{
Neural correlates of self-referential processing and implicit self-associations in chronic depression
}

Citation for published version (APA):

Renner, F., Siep, N., Lobbestael, J., Arntz, A., Peeters, F. P. M. L., \& Huibers, M. J. H. (2015). Neural correlates of self-referential processing and implicit self-associations in chronic depression. Journal of Affective Disorders, 186, 40-47. https://doi.org/10.1016/j.jad.2015.07.008

Document status and date:

Published: 01/01/2015

DOI:

10.1016/j.jad.2015.07.008

Document Version:

Publisher's PDF, also known as Version of record

Document license:

Taverne

Please check the document version of this publication:

- A submitted manuscript is the version of the article upon submission and before peer-review. There can be important differences between the submitted version and the official published version of record.

People interested in the research are advised to contact the author for the final version of the publication, or visit the DOI to the publisher's website.

- The final author version and the galley proof are versions of the publication after peer review.

- The final published version features the final layout of the paper including the volume, issue and page numbers.

Link to publication

\footnotetext{
General rights rights.

- You may freely distribute the URL identifying the publication in the public portal. please follow below link for the End User Agreement:

www.umlib.nl/taverne-license

Take down policy

If you believe that this document breaches copyright please contact us at:

repository@maastrichtuniversity.nl

providing details and we will investigate your claim.
}

Copyright and moral rights for the publications made accessible in the public portal are retained by the authors and/or other copyright owners and it is a condition of accessing publications that users recognise and abide by the legal requirements associated with these

- Users may download and print one copy of any publication from the public portal for the purpose of private study or research.

- You may not further distribute the material or use it for any profit-making activity or commercial gain

If the publication is distributed under the terms of Article $25 \mathrm{fa}$ of the Dutch Copyright Act, indicated by the "Taverne" license above, 


\title{
Neural correlates of self-referential processing and implicit self-associations in chronic depression
}

\author{
Fritz Renner ${ }^{\mathrm{a}, \mathrm{b}, *, 1}$, Nicolette Siep ${ }^{\mathrm{b}}$, Jill Lobbestael ${ }^{\mathrm{b}}$, Arnoud Arntz ${ }^{\mathrm{c}}$, Frenk P.M.L. Peeters ${ }^{\mathrm{d}, \mathrm{e}}$, \\ Marcus J.H. Huibers $\mathrm{f,g}$ \\ ${ }^{a}$ MRC Cognition and Brain Sciences Unit, Cambridge, United Kingdom \\ ${ }^{\mathrm{b}}$ Department of Clinical Psychological Science, Maastricht University, The Netherlands \\ ${ }^{\mathrm{c}}$ Department of Clinical Psychology, University of Amsterdam, The Netherlands \\ ${ }^{\mathrm{d}}$ Department of Cognitive Neuroscience, Maastricht University, The Netherlands \\ e Department of Psychiatry and Neuropsychology, University Hospital Maastricht, The Netherlands \\ ${ }^{\mathrm{f}}$ Department of Clinical Psychology, VU University Amsterdam, The Netherlands \\ ${ }^{\mathrm{g}}$ Department of Psychology, University of Pennsylvania, USA
}

\section{A R T I C L E I N F O}

\section{Article history:}

Received 20 April 2015

Received in revised form

4 July 2015

Accepted 6 July 2015

Available online 21 July 2015

Keywords:

Chronic major depressive disorder

Neuroimaging

Self-referential processing

Implicit self-associations

\section{A B S T R A C T}

Background: Patients with depression tend to process negative information with regard to the self (i.e. self-referential processing). A better understanding of the neural underpinnings of self-referential processing in patients with depression is clinically important as it can inform on potential treatment targets. Method: This fMRI study sought to study the neural correlates of self-referential processing in patients with chronic major depressive disorder $(\mathrm{cMDD})(\mathrm{n}=17)$ and non-patient controls $(n=18)$ using a passive processing paradigm. Stimuli consisted of positive, negative, negative depression related and neutral personality trait words or non-words. Participants were instructed to indicate whether a presented word was an existing word or a non-word while undergoing an fMRI scan. Participants also completed an explicit and an implicit measure of positive and negative self-associations outside the scanner.

Results: Non-patient controls had relatively increased activity in the medial prefrontal cortex (mPFC) during processing of negative depression related vs. neutral words whereas patients with cMDD had relatively decreased activity. Non-patient controls had relatively increased dorsolateral prefrontal cortex (dIPFC) activity during processing of positive vs. neutral words whereas patients with cMDD had relatively decreased activity. Explicit but not implicit self-associations with depression related words were associated with neural activity in the MPFC and the dIPFC. Limitations: The study did not include a clinical control group and therefore the specificity of findings remains unknown. Conclusions: The distinct neural processing of emotional self-relevant stimuli in the MPFC and the dIPFC in patients with cMDD might represent an emotional blunting response towards negative self-relevant stimuli.

(c) 2015 Elsevier B.V. All rights reserved.

\section{Introduction}

Patients with depression often show increased self-referential processing, defined as the experience of stimuli "as strongly related to one's own person" (Northoff, 2007, p.3) Functional neuroimaging studies in patients with depression have emphasised the importance of cortical midline structure (CMS) abnormalities

\footnotetext{
* Corresponding author at: MRC Cognition and Brain Sciences Unit, Cambridge, United Kingdom.

E-mail address: Fritz.Renner@mrc-cbu.cam.ac.uk (F. Renner).

${ }^{1}$ MRC Cognition and Brain Sciences Unit, 15 Chaucer Road, Cambridge CB2 7EF, United Kingdom.
}

during self-referential processing (for reviews see: Lemogne et al. (2012) and Nejad et al. (2013)). Whereas some studies found increased activity in the medial prefrontal cortex (MPFC) in depressed patients vs. non-patient controls during self-referential processing (Lemogne et al., 2009; Yoshimura et al., 2010) other studies found evidence for an opposite pattern (Grimm et al., 2009).

Previous neuroimaging studies on self-referential processing in depressed patients required participants to explicitly make a judgment regarding the self-relatedness of a stimulus (i.e. explicit processing paradigms). For example, in one study participants were instructed to judge whether a presented stimulus was self- 
related or not (Lemogne et al., 2011). As acknowledged by the authors, one drawback of instructing participants to engage in self-referential processing is that such instructions elicit 'controlled' rather than more 'automatic' self-referential processing (Lemogne et al., 2011). According to cognitive theories, patients with depression tend to automatically process schema congruent information (Segal, 1988). Passive processing paradigms might therefore more closely resemble the way in which persons with depression process positive and negative information. Neural correlates of these more automatic aspects of self-referential processing can be studied by presenting participants with depression with either schema congruent information (i.e. negative stimuli) or schema incongruent information (i.e. neutral or positive stimuli) during fMRI.

On a behavioural level, self-associations can also be assessed explicitly and implicitly. Explicit assessment of self-associations requires participants to reflect upon their own self and to make an explicit judgment about the self. Yet, schematic information processing operates on an automatic, implicit level (Segal, 1988). Implicit rather than explicit self-associations might therefore more closely be related to neural correlates of self-referential processing. Given that the duration of a depressive episode (i.e. chronicity) is associated with stronger implicit negative self-associations (Elgersma et al., 2013) it is intriguing to study negative self-associations and the neural correlates of self-referential processing in patients with chronic depression.

The aim of the current study was to investigate the neural correlates of self-referential processing in patients with chronic major depressive disorder (cMDD) and matched non-patient controls using a passive processing paradigm. In addition, we examined explicit and implicit self-associations (assessed outside the scanner) with positive and negative personality traits in the same group of participants. We hypothesised that (1) patients with cMDD show a differential activation pattern in areas of the brain that have previously been associated with self-referential processing (i.e. CMS) during presentation of schema-congruent (negative and depression-related negative trait words) vs. schema incongruent (neutral or positive trait words) compared to non-patient controls; (2) neural activity in CMS is positively correlated with explicit and implicit self-associations of personality traits, as assessed outside the scanner.

\section{Method}

\subsection{Participants}

Eighteen patients with cMDD and 18 non-patient controls matched on age, gender, education level and left/right-handedness were recruited for this study. One left handed patient could not be matched to a left handed non-patient control and was therefore matched to a right handed non-patient control participant. After data acquisition, one cMDD patient had to be excluded because of technical problems with the MRI scans. The final sample analysed therefore comprised 18 non-patient controls and 17 patients with cMDD. The study protocol was approved by the medical ethical committee of the academic University Hospital Maastricht, the Netherlands and all participants enroled in the study signed written informed consent.

Patients were recruited from a specialized secondary mental health facility in the Netherlands (Riagg Maastricht) as part of a treatment study (Clinicaltrials.gov identifier: NCT01153867). Scanning of patients took place prior to the intervention phase of the study. Patients were included if they met the DSM-IV criteria for chronic Major Depressive Disorder (i.e. if they met the criteria for Major Depressive Disorder for two years or longer), assessed with the Structured Clinical Interview for DSM-IV axis I disorders (SCID-I) and if they scored 20 or higher on the Beck Depression Inventory second edition (BDI-II), indicating moderate levels of depression. Patients were excluded if they were suicidal or if they fulfilled DSM-IV criteria for bipolar disorder, psychotic disorders, alcohol or substance dependence, autism spectrum disorders or cluster-A or cluster-B personality disorder as assessed with the SCID-II interview. One patient with co-morbid borderline personality disorder was included in error but is analysed here. Patients who took antidepressant medications were excluded, unless they were stable on medication for 3 months or longer prior to study intake. Nine (53\%) patients with cMDD took antidepressant medication (8 SSRI'S 1 TCA) and were stable on medication for at least 3 months, except for one patient for whom the medication dosage was adjusted two month prior to the study.

Non-patient controls were recruited via poster advertisements and a volunteer database. Non-patient controls were excluded if they met the DSM-IV criteria for a current axis-I disorder or any lifetime mood disorder.

Table 1 provides an overview of the demographic and clinical characteristics of the sample.

\subsection{Materials}

\subsubsection{Beck Depression Inventory second edition}

The Beck Depression Inventory second edition (BDI-II) is a 21item self-report instrument assessing depressive symptom severity (Beck et al., 1996). In the present study depressive symptom severity during the past 7 days were assessed. The Dutch BDI-II that was used in the present study has good psychometric properties (van der Does, 2002).

\subsubsection{Implicit task - single-category implicit associations test}

A depression specific single-category implicit association test (SC-IAT) was used to assess implicit negative self-associations (outside the scanner). The task started with a practise block in which 12 positive and 12 negative words (attributes) were presented, followed by two test blocks. Test blocks included a third word category (self-stimuli). During the test blocks the self-stimuli shared a response key with either the positive or the negative attributes (counterbalanced). Each test block started with 12

Table 1

Demographic and clinical characteristics of the sample.

\begin{tabular}{|c|c|c|c|c|}
\hline Measure & $\begin{array}{l}\text { Patients } \\
(n=17)\end{array}$ & $\begin{array}{l}\text { Controls } \\
(n=18)\end{array}$ & $\begin{array}{l}t \text {-test ( } p \text { - } \\
\text { Value) }\end{array}$ & $\begin{array}{l}\chi^{2}(p- \\
\text { Value })\end{array}$ \\
\hline Age, $M$ (SD) & 40.41 (17.77) & 42.67 (18.73) & .72 & - \\
\hline Gender, $n$ & & & - & .92 \\
\hline Female & 12 & 13 & & \\
\hline Male & 5 & 5 & & \\
\hline Education level, $\mathrm{n}$ & & & - & .80 \\
\hline Low & 1 & 2 & & \\
\hline Medium & 5 & 4 & & \\
\hline High & 11 & 12 & & \\
\hline BDI-II score & 30.47 (9.68) & $2.67(2.77)$ & $<.001$ & - \\
\hline ADM use, $n$ & 9 & - & & \\
\hline SSRI & 8 & - & & \\
\hline TCA & 1 & - & & \\
\hline
\end{tabular}

Note. $\mathrm{ADM}=$ Antidepressant medication; $\mathrm{BDI}-\mathrm{II}=$ Beck Depression Inventory second edition; SSRI=Selective Serotonin Reuptake Inhibitor; TCA=Tricyclic Antidepressant. 
practice trials ( 7 attributes and 5 self-stimuli), followed by 72 critical trials consisting of 30 -self-stimuli and 42 attributes. Negative stimuli reflected main themes in depression (rejected, harmful, worthless, redundant, helpless, and vulnerable) and positive stimuli represented their counterparts (beloved, pleasant, powerful, successful, perfect, and valuable). In addition six selfstimuli were selected: I, me, self, my, own, and mine. A more detailed description of the task design is provided elsewhere (Lemmens et al., 2014).

\subsection{3. fMRI self-referential processing task word stimuli}

The word stimuli for the self-referential processing task were selected from Andersons's list of personality trait words (Anderson, 1968) and from the SC-IAT (described above). Based on the mean valence and arousal ratings during a pilot test in an independent sample $(n=13), 80$ personality trait words were selected and categorized into four equal unambiguous categories: (1) positive words (e.g. happy); (2) general negative words (e.g. arrogant); (3) depression related negative words (e.g. worthless); (4) neutral words (e.g. moderate). ${ }^{2}$ Care was taken to match words on word length and arousal levels, however, neutral words were rated as less arousing compared to positive and negative words $(p<.01$ and $p<.001$, respectively). Negative words were rated as slightly more arousing compared to negative depression related words $(p<.01)$. Participants were also presented with 20 nonwords (random composition of letters) and instructed to press a button whenever a non-word appeared, in order to keep focused on the task.

\subsection{4. $f M R I$ passive self-referential processing task design}

Personality trait words (positive, negative general, negative depression related and neutral) and non-words were presented in a slow-event related design (presentation duration $4000 \mathrm{~ms}$ ). Word categories were presented in a fixed order, which differed per run, with personality trait words within categories and nonwords presented randomly. Stimuli presentation was separated by a fixation cross with a random presentation duration of 2000 , 3000,4000 and $5000 \mathrm{~ms}$. The task consisted of two runs (counterbalanced between participants) with a duration of 12 min per run. In each run 100 words ( 20 from each category) were projected to a screen behind the scanner that participants viewed through an angled mirror. In the second run the same stimuli set as in the first run was presented in a different random order.

\subsection{Procedure}

As part of the same scanning sessions, participants first underwent two 6 min resting state scans (results reported separately) and an anatomical scan. Before the self-referential processing task, participants were instructed to read each word and to press a button with their left index finger when they detect a nonword. Between the two runs participants underwent a diffusion tensor imaging scan (results not reported here). Overall, the scanning session lasted about $60 \mathrm{~min}$. Following the scanning session participants rated the valence and self-descriptiveness of each personality trait word on a scale from 1 to 5 (explicit assessment of negative self-associations) and non-patient controls completed the SC-IAT (implicit assessment of negative self-associations). Patients completed the SC-IAT on a separate day as part of a larger assessment.

\footnotetext{
${ }^{2}$ A list of all 80 personality trait words with valence and arousal ratings can be requested from the corresponding author.
}

\subsection{1. fMRI data acquisition}

Anatomical images were acquired using a Magnetom Allegra 3 T scanner (Siemens Healthcare, Netherlands) with a T1-weighted gradient echo (196 slices, $T R=2250 \mathrm{~ms}, \mathrm{TE}=26 \mathrm{~ms}$, flip angle $=90^{\circ}$, field of view $=256 \mathrm{~mm}$ and voxel dimensions $\left.1 \times 1 \times 1 \mathrm{~mm}^{3}\right)$. Two functional runs were obtained with a $\mathrm{T}_{2}^{*}$ weighted echo planar imaging sequence consisting of 32 slices with a $3 \mathrm{~mm}$ slice thickness. TR was set at $2000 \mathrm{~ms}$, with an TE of $30 \mathrm{~ms}$ and a flip angle of $90^{\circ}$. The field of view was $192 \mathrm{~mm}$ with a voxel size of $3 \times 3 \mathrm{~mm}^{2}$ isotropic resolution. During each run 380 volumes were acquired. A slice tilt correction of -30 was used to minimise inhomogeneity artefacts (Weiskopf et al., 2006).

\subsection{2. fMRI data pre-processing}

Data pre-processing and analyses were conducted with Brainvoyager QX v2.4 (Brain Innovations, Maastricht, The Netherlands). The first two volumes of the functional images were omitted due to an unstable signal. For the functional data a slice scan timing correction was performed by sinc interpolation and the data was motion corrected using a 3D motion correction with sinc interpolation and high-pass temporal filtering. The data was smoothed using a $4 \mathrm{~mm}$ full-width-at-half-maximum Gaussian filter. The skull was removed by an automated brain peeling procedure. Functional images were then co-registered to structural images and subsequently normalised using the Talairach and Tournoux transformation procedure.

\subsection{3. fMRI analyses}

FMRI data analyses were conducted in three steps. First, individual participants' BOLD signals were modelled in an eventrelated design using a general linear model (GLM) with 5 predictors, denoting the personality trait words in either positive, negative general, negative depression related, neutral and nonwords. Conditions in the GLM were modelled as boxcar functions and convolved with a 2-gamma hemodynamic response function. First-level GLM analyses conducted on individual participants' fMRI signal were submitted to a second-level random effects analysis, treating participants as a random factor in order to identify brain regions involved in processing of personality trait words in general. In these analyses all personality trait words were contrasted with the non-words. A resulting map of brain regions indicating positive activity was selected at a conservative False Discovery Rate (FDR) of 0.005. Based on the resulting map a VTC mask was created and subsequent analyses focused on group $\mathrm{X}$ word type interactions within this mask. Volumes-of-interest (VOIs) resulting from the group $\mathrm{X}$ word type interaction analysis were identified and defined within this map, using a cluster size threshold of 3 and a significance level of $p<.025$. Using this approach a total of 2 VOIs were identified. Within each VOI the beta weights were averaged across participants for each category of word-stimuli. To test our hypothesis of group X word type interactions, simple effects analyses with a Bonferroni adjusted significance level alpha (.05/3) were conducted. To visualize group X word type interactions bar-plots were created for each VOI displaying the mean signal change of critical word stimuli vs. neutral words for each group.

\subsubsection{Analyses of implicit and explicit self-associations}

The SC-IAT effect was analysed using the improved D-score algorithm (Greenwald et al., 2003). Higher scores represent stronger self-associations with positive words than with negative words. Independent sample $t$-tests were used to test for differences in explicit and implicit self-associations between the two groups. 


\section{Results}

\subsection{Explicit self-associations and valence ratings}

Valence and self-relatedness ratings are summarised in Fig. 1. Patients rated general negative and negative depression related words as more self-descriptive than non-patient controls, $t$ (33) $=-3.48, p=.001,95 \%$ CI $[0.19,0.72], d=1.18$, and $t(33)=-$ $9.09, p<.001,95 \% \mathrm{CI}[1.13,1.78], d=3.07$ respectively. Patients also rated the negative depression related words as more self-descriptive than general negative words, compared to non-patients, $t$ $(33)=6.73, p<.001,95 \%$ CI $[0.70,1.30], d=2.28$. Controls rated positive trait words more self-descriptive compared to patients, $t$ (33) $=6.22, p<.001,95 \% \mathrm{CI}[-1.18,-0.60], d=2.10$. There were no statistically significant differences in the self-descriptiveness ratings of neutral words, $t(33)=-0.12, p=.91,95 \% \mathrm{CI}[-0.24,-0.60]$, $d=0.04$. Valence ratings did not differ between the two groups. Both groups rated the general negative and the negative depression related words as more negative than the neutral words, $t$ $(34)=-15.94, p<.001,95 \% \mathrm{CI}[-1.48,-1.15], d=5.39$ and $t$ $(34)=-16.11, p<.001,95 \%$ CI $[-1.36,-1.05], d=5.45$, respectively and positive trait words as more positive than the neutral words, $t(34)=13.96, p<.001,95 \%$ CI $[0.83,1.12], d=4.72$.

\subsection{Implicit self-associations}

Implicit self-associations on the SC-IAT did not differ between patients $(M=-0.08, \mathrm{SD}=0.37)$ and non-patient controls $(M=0.09$, $\mathrm{SD}=0.35 ; t(33)=-1.32, p=.20,95 \% \mathrm{CI}[-0.41,0.09], d=0.45)$.

\subsection{Engagement in the passive self-referential processing task}

To ensure that patients and controls equally engaged in the passive self-referential processing task, the number of correctly identified non-words and the number of wrongly identified nonwords was compared between patients and controls. On average, the number of correctly identified non-words did not differ between patients and controls, $t(33)=1.55, p=.13$, and neither did the number of wrongly identified non-words, $t(33)=0.83, p=.41$. On average participants missed $1.33 / 20$ non-words indicating good task performance.

\section{4. fMRI results}

The whole brain analyses, contrasting personality-trait words with non-words across all participants, revealed a number of brain areas, including cortical midline structures (MPFC, MOFC, and PCC)

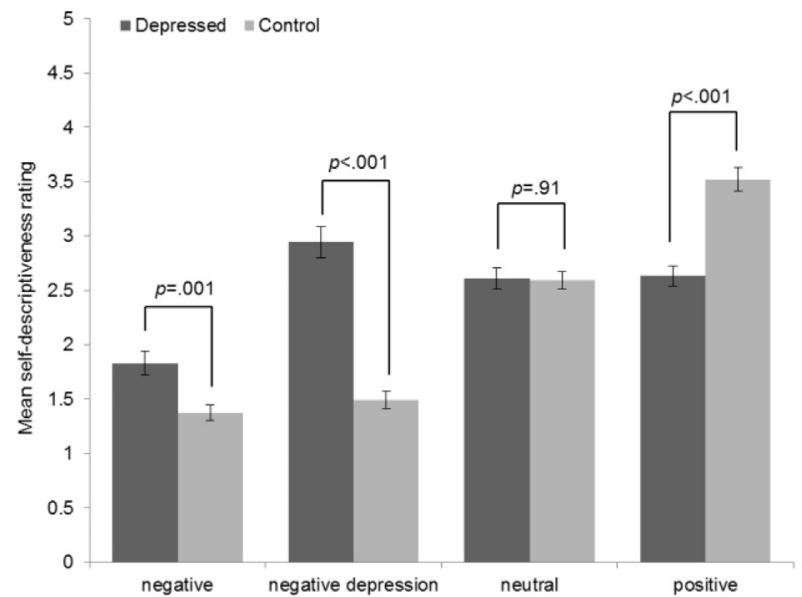

Table 2

Areas selected for mask showing significant word X non-word interactions.

\begin{tabular}{lllrl}
\hline Brain region & $\mathrm{L} / \mathrm{R}$ & $\begin{array}{l}\text { Talairach coordinates } \\
(x, y, z)\end{array}$ & BA & $\begin{array}{l}\text { Cluster size } \\
\text { (voxels) }\end{array}$ \\
\hline $\begin{array}{l}\text { Bilateral posterior cingu- } \\
\text { late cortex }\end{array}$ & $\mathrm{L} / \mathrm{R}$ & $-4,-55,16$ & 23 & 7152 \\
$\begin{array}{l}\text { Ventromedial prefrontal } \\
\quad \text { cortex }\end{array}$ & $\mathrm{L} / \mathrm{R}$ & $-5,44,-1$ & 32 & 6431 \\
Anterior prefrontal cortex & $\mathrm{L}$ & $-11,48,11$ & 10 & 91 \\
Dorsolateral prefrontal & $\mathrm{L}$ & $-24,24,43$ & 8 & 451 \\
$\quad$ cortex & & & & \\
Fusiform gyrus & $\mathrm{L}$ & $-32,-36,-10$ & 37 & 95 \\
$\quad$ Middle temporal gyrus & $\mathrm{L}$ & $-44,-72,24$ & 39 & 406 \\
Superior temporal gyrus & $\mathrm{L}$ & $-47,14,-26$ & 38 & 252 \\
Inferior temporal gyrus & $\mathrm{L}$ & $-62,-5,-17$ & 21 & 818 \\
\hline
\end{tabular}

and parts of the left dorsolateral prefrontal cortex, pre-motor cortex and the left temporal lobe (see Table 2). Two regions within the VTC mask showed significant group $X$ word type interactions, the medial prefrontal cortex $(F(3,31)=3.38, p=.031)$ and dorsolateral prefrontal cortex $(F(3,31)=3.19, p=.037$; Table 3$)$. Subsequent tests contrasting each category of emotional personality trait words with neutral words (positive vs. neutral; general negative vs. neutral; depression related negative vs. neutral), between and within groups, were conducted at a Bonferroni adjusted significance level alpha of $.016(.05 / 3)$. Thus only $p$-values $<.016$ were considered statistically significant.

\subsection{Medial prefrontal cortex}

Non-patient controls had a greater BOLD signal in the left mPFC during processing of negative depression related vs. neutral word stimuli whereas patients with cMDD had a decreased BOLD response during processing of negative depression related vs. neutral word stimuli, $F(1,33)=10.38, p=.003$. This group difference was also reflected in a significant negative correlation between BOLD signal changes in negative depression related vs. neutral words and the BDI-II total score $(r=-.42, p=.011)$, showing that higher depressive symptom severity, across all participants, was associated with decreased BOLD signal for this contrast. The BOLD signal of the two groups did not differ significantly during processing of positive vs. neutral stimuli, $F(1,33)=3.65, p=.064$ or during processing of general negative vs. neutral word stimuli, $F(1$, 33 ) $=5.78, p=.022$ (see Fig. 2). Within group comparisons of emotional personality trait words vs. neutral words revealed that non-patient controls showed an increased BOLD signal in the left $\mathrm{mPFC}$ during processing of negative depression related vs. neutral

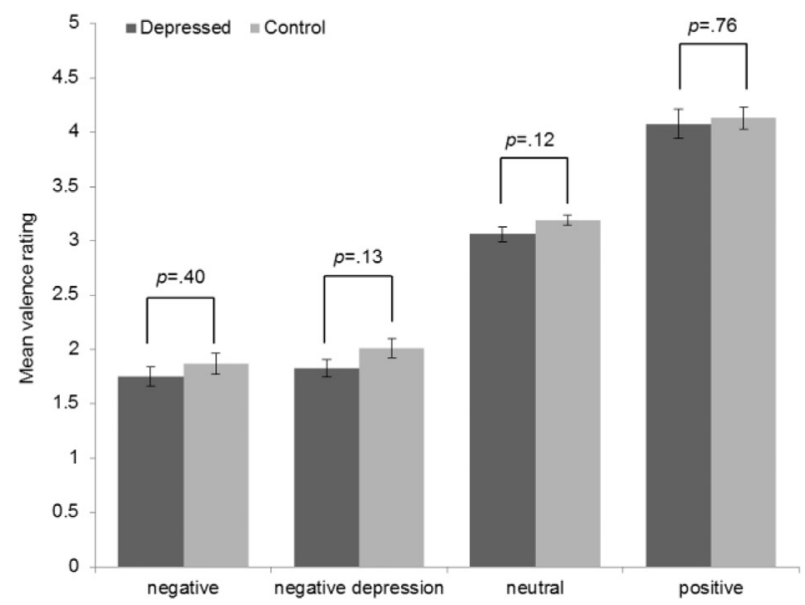

Fig. 1. Mean self-descriptiveness (left side) and valence (right side) ratings of general negative, negative depression related, neutral and positive words. 
Table 3

Areas showing significant personality group X word type interactions.

\begin{tabular}{|c|c|c|c|c|}
\hline Brain region & $\mathrm{L} / \mathrm{R}$ & $\begin{array}{l}\text { Talairach coordinates } \\
(x, y, z)\end{array}$ & BA & $\begin{array}{l}\text { Cluster size } \\
\text { (voxels) }\end{array}$ \\
\hline Medial prefrontal cortex & $\mathrm{L}$ & $-8,60,10$ & 10 & 111 \\
\hline $\begin{array}{l}\text { Premotor cortex/dorsolateral } \\
\text { prefrontal cortex }\end{array}$ & $\mathrm{L}$ & $-25,17,39$ & 8 & 139 \\
\hline
\end{tabular}

Note. $\mathrm{L} / \mathrm{R}=$ Left/Right; $\mathrm{BA}=$ Brodmann area; Talairach coordinates refer to the centre of gravity of each VOI.

personality trait words, $t(18)=-2.93, p=.009$. The other within group contrasts for non-patient control participants were not significant (all $p$-values $>.016$ ). Within the group of depressed patients none of the within group contrasts were significant (all $p$ values $>.016$ ). Moreover, post-hoc tests revealed that the group $\mathrm{x}$ negative word type (general negative vs. depression related words) contrast failed to reach significance, $F(1,33)=0.02, p=.876$. Similarly, the group $\mathrm{x}$ positive vs. negative depression words contrast failed to reach significance, $F(1,33)=0.79, p=.381$.

\subsection{Premotor cortex/dorsolateral prefrontal cortex}

Non-patient controls showed a greater BOLD signal in the left dIPFC during processing of positive vs. neutral word stimuli whereas patients with cMDD had a decrease in BOLD signal during processing of positive vs. neutral word stimuli, $F(1,33)=6.72$, $p=.014$. This group difference was also reflected in a significant correlation between BOLD signal changes in positive vs. neutral words and the BDI-II total score $(r=-.40, p=.016)$, showing that higher BDI-II scores were associated with decreased BOLD signal for this contrast. The BOLD signal of the two groups did not differ statistically significantly during processing of general negative vs. neutral stimuli, $F(1,33)=0.79, p=.380$ or during processing of negative depression vs. neutral word stimuli, $F(1,33)=3.20$, $p=.083$ (see Fig. 2). Within group comparisons of emotional personality trait words vs. neutral words for the non-patient control group were not significant (all $p$-values $>.016$ ). Within the group of depressed participants none of the within group contrasts were significant (all $p$-values $>$.016). Although the groups differed significantly only for the positive vs. neutral words, the evidence for the specificity of the effect for positive words was limited as the groups did not differ significantly on the positive vs. negative
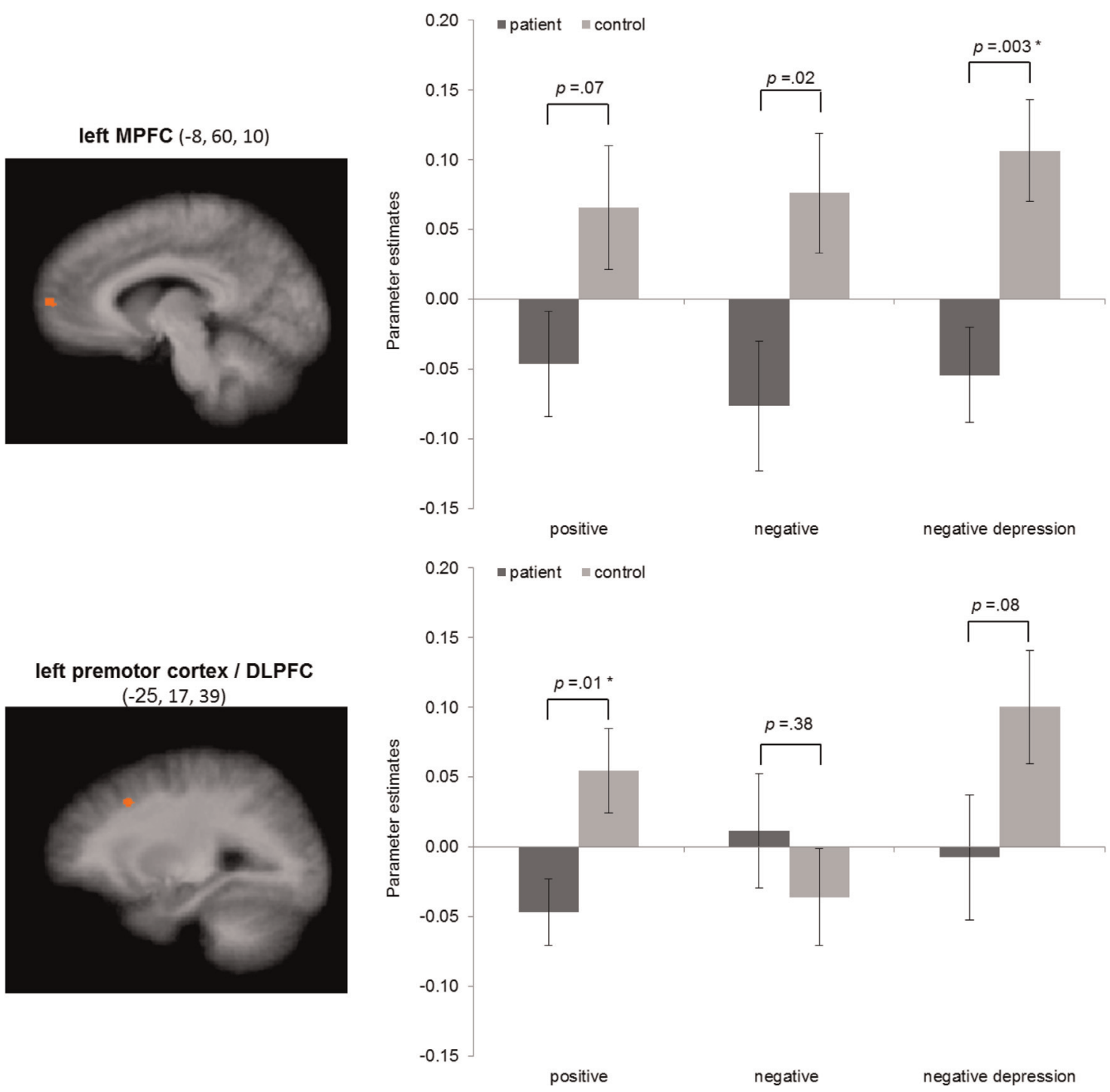

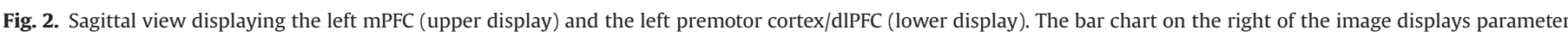

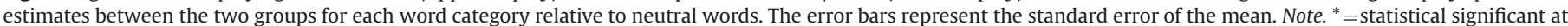
a Bonferroni adjusted significance level alpha of .016. 
depression word categories, $F(1,33)=0.89, p=.887$.

\subsection{Correlations between implicit and explicit self-associations and BOLD signal change}

To avoid an inflation of the Type-I error rate only correlations within contrasts that were significant in the initial analyses were investigated.

Within the mPFC the self-descriptiveness ratings of negative depression related words were negatively correlated with BOLD signal changes during processing of negative depression related vs. neutral words $(r=-.34, p=.045)$. This shows that explicit ratings of negative depression words as self-descriptive, across all subjects, were associated with decreased BOLD signal during processing of negative depression related words vs. neutral words.

Within the dIPFC there was a significant negative correlation between self-descriptiveness ratings of negative and negative depression related words and BOLD signal change during processing of positive vs. neutral word stimuli $(r=-.40, p=.018$ and $r=-.46, p=.005)$. This shows that explicit ratings of negative (depression related) words as self-descriptive, across all subjects, were associated with decreased BOLD signal during processing of positive vs. neutral words.

Implicit self-associations did not correlate statistically significantly with parameter estimates for BOLD signal change in the $\mathrm{mPFC}$ or in the dlPFC during processing of emotional vs. neutral words (all $p$-values $>.05$ ).

\subsection{Correlations between use of antidepressants and BOLD signal change}

About half (53\%) of the patients in this study took antidepressant medication at the time of the study. None of the within group contrasts of BOLD signal change for emotional vs. neutral words in the MPFC and dIPFC were correlated with antidepressant medication use (all $p$-values $>.05$ ).

\section{Discussion}

The aim of this fMRI study was to explore the neural correlates of self-referential processing in patients with chronic major depressive disorder (cMDD) and to determine its association with explicit and implicit measures of self-associations (assessed outside the scanner). Processing of negative depression related words vs. neutral words was associated with relatively more neural activity in the left medial prefrontal cortex (mPFC) in non-patient controls and with relatively lower neural activity in patients with cMDD. Explicit, but not implicit, self-associations with negative depression words were associated with decreased BOLD signal change in the mPFC during processing of negative depression related words. The evidence for the stimulus-specificity was mixed as only the negative depression related words vs. neutral words contrast reached Bonferroni-corrected significant difference between groups. However, groups did not differ significantly as to the negative depression vs. general negative words and negative depression vs. positive words contrasts.

There was a significant interaction between word category and group in the left dorsolateral prefrontal cortex (dlPFC). Processing of positive personality trait words vs. neutral words was associated with a relative increased neural activity in the dIPFC in nonpatient controls and with a relative decrease in neural activity in patients with cMDD. In line with these findings, one previous neuroimaging study in patients with a milder form of chronic depression (dysthymic disorder) found hypoactivity in the dlPFC compared to non-patient controls during processing of positive pictures (Ravindran et al., 2009). It has been suggested that reduced activity in the dIPFC during processing of positive vs. neutral stimuli might reflect decreased attention towards positive stimuli in patients with depression (Ravindran et al., 2009). In line with these findings, stimulation of the left dlPFC with repetitive Transcranial Magnetic Stimulation results in decreased depressive symptoms in patients with treatment-resistant depression (Pascual-Leone et al., 1996; Fitzgerald et al., 2003; Avery et al., 2006) and there is evidence that dIPFC activity in patients with depression increases during treatment with antidepressants (Fitzgerald et al., 2008). It should be noted however that the evidence for the word category specificity of the dIPFC response was limited, as the response to positive words when compared to other emotional word categories did not differ significantly between groups.

The finding of the current study that processing of emotional relative to neutral words was generally associated with decreased BOLD signal change in patients suggests that patients with chronic depression show a general blunting response when confronted with emotional stimuli. It has been argued previously that MDD is characterized by blunted emotional reactivity, not only to positive emotional stimuli but also towards negative emotional stimuli (Rottenberg et al., 2005), a phenomenon known as the emotioncontext insensitivity hypothesis (Rottenberg et al., 2005). This hypothesis has been supported for self-reported emotions, as well as for physiological emotional response indicators in a meta-analysis (Bylsma et al., 2008). Blunted emotional responses to everyday negative stressors have also been associated with depression chronicity (Peeters et al., 2010).

Although our findings of decreased signal strength in patients with cMDD in the left MPFC were only significant for negative depression related words, it should be noted that the direction of signal change between the two groups was similar for positive and negative words, and posthoc comparisons between the emotional word categories did not support word specificity (Fig. 2). The fact that the pattern was similar for positive and general negative words further support the idea that patients with chronic depression show a blunted response to all emotional stimuli although this might be more pronounced for negative depression related stimuli.

Different explanations might account for differences between previous studies assessing neural correlates of self-referential processing in depression and the results of the current study. Previous studies used explicit paradigms to study neural correlates of self-referential processing, instructing participants to process stimuli with regard to the self. In contrast, in the current study a passive processing paradigm was used to allow for a more 'automatic' self-referential processing during the presentation of schema congruent personality trait words. The subjective word evaluation in the current study indicated that, on an explicit level, depressed patients indeed described negative depression related personality trait words as more self-descriptive (i.e. schema congruent), whereas non-patient controls described positive personality words as more self-descriptive. However, two previous studies have shown that passive processing of self-relevant information relies on the same neural structures as self-referential processing in explicit paradigms (Moran et al., 2009; Rameson et al., 2010). It is therefore unlikely that differences in the experimental paradigm account for differences with findings of previous studies.

Divergent findings with respect to $\mathrm{MPFC}$ activity during selfreferential processing in depressed and non-depressed participants have also been explained in terms of a functional difference between the dorsal and the ventral mPFC (Lemogne et al., 2012). In this model, elevated ventral mPFC activation is assumed to represent automatic aspects of self-referential processing, whereas dorsal mPFC activity represents strategic aspects of self-focus 
(Lemogne et al., 2012). In this context, the relatively decreased activity in the ventral mPFC in patients with depression that was found in the current study might be explained by the use of a "shallow" tasks, such as the passive processing task used here, which might allow for more spontaneous self-referential processing in patients with depression such that task stimuli do not induce strong signal changes (e.g. Lemogne et al. (2012)).

Another explanation for divergent findings might be that previous studies included patients with depression in general without a specific focus on patients with chronic depression (for a review see: Lemogne et al. (2012)). It is possible that due to the long duration of depressive episodes (i.e. at least two years), patients with cMDD display a more emotionally numbing response toward emotional stimuli than patients with depression with shorter episode duration (i.e. less than two years).

On an implicit level there were no differences between the two groups with regard to negative self-associations (assessed outside the scanner). These findings are in line with one previous study that used the same depression specific SC-IAT in patients with episodic depression (Lemmens et al., 2014). Based on previous research showing that implicit depressive-self associations are associated with depressive episode duration (Elgersma et al., 2013), we expected that chronically depressed patients in the current study would show increased implicit negative self-associations that would correlate with brain responses associated with self-referential processing. Future studies should aim to directly compare implicit negative self-associations in patients with nonchronic depression and patients with chronic depression.

\subsection{Limitations}

First, the current study did not include a clinical control group and it therefore remains unclear how specific our findings are with respect to chronic depression. It would have been interesting, for example, to include a non-chronic depression clinical control group to determine the specificity of the results. Second, about half of the patients in the current study took antidepressant medication at the time when the study was conducted and it is unclear if this has influenced the results. However, note that antidepressant medication use was not associated with the main findings. Third, the initially intended matching did not succeed completely, as one cMDD participant had to be excluded due to technical problems and one other cMDD participant could not be matched on handedness.

Clinically, our findings suggest that patients with chronic depression show a blunted response when confronted with emotional stimuli. Emotional processing is an important aspect of emotion focused treatments for depression (Greenberg and Watson, 2006) and in treatments with a strong experiential component, such as schema therapy (Young et al., 2003). The current findings therefore support the idea that treatment for chronic depression could benefit from a stronger focus on emotional processing (e.g. Renner et al. (2013)).

In conclusion, our findings suggest that chronic depression is characterized by a distinct neural processing of emotional selfrelevant stimuli in the left $\mathrm{mPFC}$ and left dIPFC. The observed pattern might represent an emotional numbing response towards emotional stimuli in general. Future studies should determine the specificity of these findings with respect to chronic depression and the stability of findings over a course of treatment for depression that has a strong focus on emotional processing techniques such as schema therapy or emotion focused therapy for depression.

\section{Author disclosure}

None

\section{Role of the funding source}

This work was supported by Maastricht University, The Netherlands and by the Academic Community Mental Health Centre (RIAGG) Maastricht.

\section{Author's contributions}

Study concept and design: All authors. Acquisition and analysis of data: Drs. Renner and Siep. Interpretation of the data: All authors. Drafting of the manuscript: Renner and Siep. Critical revision of the manuscript: All authors.

\section{Conflict of interest}

None of the authors to this manuscript has any potential conflict of interest or had any potential conflict within the past three years of beginning the work, in cluding any financial, personal, or other relationship with people or organisations that might be interpreted as influencing our research.

\begin{abstract}
Acknowledgements
We are grateful to our colleagues at Maastricht University who supported this study: Annie Hendriks and Annie Raven helped with patient recruitment; Danielle Jongen assisted with recruitment of matched controls; Rosanne Janssen developed the infrastructure for online data collection; Anne Roefs programmed the original version of the single-category implicit associations test; Michiel Vestjens programmed an online version of the single-category implicit associations test that was used in the current study. Thanks are also due to our colleagues at the Riagg Maastricht who helped to recruit patients and conducted clinical interviews for this study.
\end{abstract}

\section{References}

Anderson, N.H., 1968. Likableness ratings of 555 personality-trait words. J. Personal. Soc. Psychol. 9 (3), 272-279.

Avery, D.H., et al., 2006. A controlled study of repetitive transcranial magnetic stimulation in medication-resistant major depression. Biol. Psychiatry 59 (2), 187-194.

Beck, A.T., Steer, R.A., Brown, G.K., 1996. Manual for the Beck Depression InventoryII. San Antonio, TX

Bylsma, L.M., Morris, B.H. Rottenberg J. 2008. A meta-analysis of emotional reactivity in major depressive disorder. Clin. Psychol. Rev. 28 (4), 676-691.

van der Does, A.J.W., 2002. Handleiding: De Nederlandse versie van de Beck Depression Inventory, 2de Editie. (The Dutch Version of the Beck Depression Inventory, 2nd ed.). Swets and Zeitlinger B.V., Lisse.

Elgersma, H.J., et al., 2013. Hidden scars in depression? Implicit and explicit selfassociations following recurrent depressive episodes. J. Abnorm. Psychol. 122 (4), 951-960

Fitzgerald, P.B., et al., 2003. Transcranial magnetic stimulation in the treatment of depression: a double-blind, placebo-controlled trial. Arch. Gen. Psychiatry 60 (10), 1002-1008.

Fitzgerald, P.B., et al., 2008. A meta-analytic study of changes in brain activation in depression. Hum. Brain Mapp. 29 (6), 683-695.

Greenberg, L.S., Watson, J.C., 2006. Emotion-Focused Therapy for Depression. American Psychological Association, Washington.

Greenwald, A.G., Nosek, B.A., Banaji, M.R., 2003. Understanding and using the implicit association test: I. An improved scoring algorithm. J. Pers. Soc. Psychol. 85 (2), 197-216.

Grimm, S., et al., 2009. Increased self-focus in major depressive disorder is related to neural abnormalities in subcortical-cortical midline structures. Hum. Brain Mapp. 30 (8), 2617-2627.

Lemmens, L.H.J.M., et al., 2014. The value of an implicit self-associative measure specific to core beliefs of depression. J. Behav. Ther. Exp. Psychiatry 45 (1), $196-202$.

Lemogne, C., et al., 2009. In search of the depressive self: extended medial prefrontal network during self-referential processing in major depression. Soc. Cogn. Affect. Neurosci. 4 (3), 305-312.

Lemogne, C., et al., 2011. Negative affectivity, self-referential processing and the cortical midline structures. Soc. Cogn. Affect. Neurosci. 6 (4), 426-433.

Lemogne, C., et al., 2012. Medial prefrontal cortex and the self in major depression. J. Affect. Disord. 136 (1-2), e1-e11.

Moran, J.M., Heatherton, T.F., Kelley, W.M., 2009. Modulation of cortical midline structures by implicit and explicit self-relevance evaluation. Soc. Neurosci. 4 (3), 197-211.

Nejad, A.B., Fossati, P., Lemogne, C., 2013. Self-referential processing, rumination, 
and cortical midline structures in major depression. Front. Hum. Neurosci. 7, 666.

Northoff, G., 2007. Psychopathology and pathophysiology of the self in depression neuropsychiatric hypothesis. J. Affect. Disord. 104 (1-3), 1-14.

Pascual-Leone, A., et al., 1996. Rapid-rate transcranial magnetic stimulation of left dorsolateral prefrontal cortex in drug-resistant depression. Lancet 348 (9022) 233-237.

Peeters, F., et al., 2010. Ambulatory emotional reactivity to negative daily life events predicts remission from major depressive disorder. Behav. Res. Ther. 48 (8), 754-760.

Rameson, L.T., Satpute, A.B., Lieberman, M.D., 2010. The neural correlates of implicit and explicit self-relevant processing. NeuroImage 50 (2), 701-708.

Ravindran, A.V., et al., 2009. Toward a functional neuroanatomy of dysthymia: a functional magnetic resonance imaging study. J. Affect. Disord. 119 (1-3), 9-15.
Renner, F., et al., 2013. Treatment for chronic depression using schema therapy. Clin. Psychol. Sci. Pract. 20, 166-180.

Rottenberg, J., Gross, J.J., Gotlib, I.H., 2005. Emotion context insensitivity in major depressive disorder. J. Abnorm. Psychol. 114 (4), 627-639.

Segal, Z.V., 1988. Appraisal of the self-schema construct in cognitive models of depression. Psychol. Bull. 103 (2), 147-162.

Weiskopf, N., et al., 2006. Optimal EPI parameters for reduction of susceptibilityinduced BOLD sensitivity losses: a whole-brain analysis at $3 \mathrm{~T}$ and $1.5 \mathrm{~T}$. Neurolmage 33 (2), 493-504.

Yoshimura, S., et al., 2010. Rostral anterior cingulate cortex activity mediates the relationship between the depressive symptoms and the medial prefrontal cortex activity. J. Affect. Disord. 122 (1-2), 76-85.

Young, J.E., Klosko, J., Weishaar, M.E., 2003. Schema Therapy: a Practitioner's Guide. Guilford Press, New York. 